\title{
Simulation of 3-phase matrix converter using space vector modulation
}

\author{
K. Selvakumar, R. Palanisamy, Arul Rayappan Stalin, P. Gopi, P. Ponselvin, K. Saravanan \\ Department of EEE, SRM Institute of Science and Technology, Kattankulathur, Chennai, India
}

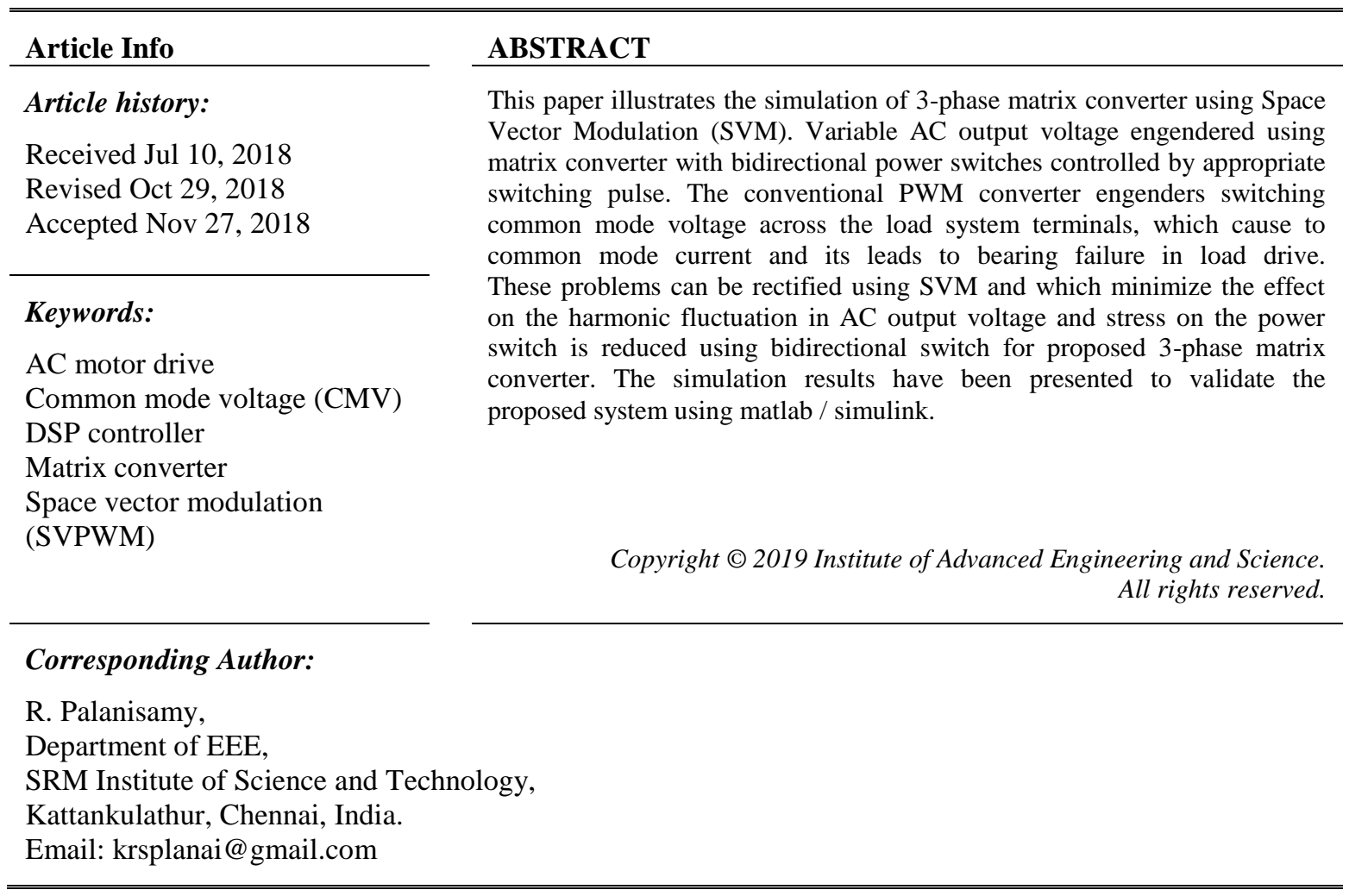

\section{INTRODUCTION}

Nowadays power electronic converters are arranged in various uses such as industrial, medical, power system applications, energy transportation, and railway applications. Optimization of power electronic converter devise and operation is important to improve power processing level to meet the demand and to develop the quality of power [1]. Among that inverter are extensively used in numerous applications in which the essential voltage is AC always in nature [2], [3]. Even though most of drives required DC source to operate in four quadrants, so rectifier prepared to generate DC voltage [4]. Basically for converting AC-AC, the conventional converters cyclo converter and ac voltage controller utilised, but these converter not able to provide control on frequency and voltage with reduced harmonics and controlled output AC current [5].

The matrix converter is a to convert AC-AC source with minimized ripple content [6]. It has merit over conventional rectifier - inverter power frequency combination, with reduced higher order harmonics and no lower harmonics [7]. The matrix converter has main features are input AC source is fully controlled, bidirectional energy flow capability, input power factor can be controlled, exclusion of dc link filters and power devices can be used with zero switching due to that power loss is minimised [8-9]. The main disadvantage of matrix converter is require more power semiconductor devices compare to traditional rectifier-inverter pair [10].

Pulse width modulation (PWM) is generally used switching strategy to maintain voltage amplitude and frequency and fast dynamic response. Due to these conventional PWM methods, the circulating current in the converter system starts increase [11], [12]. Common mode voltage (CMV) of the converter also increases; it leads to failure of motor bearings and increase in electromagnetic interference problems. 
For eradicate these problems the additional filter components are added, which diminish the power density and increase initial cost of the system [13], [14]. For several applications the multilevel converters are used to decrease the CMV issue, at same time complexity increases in PWM switching pulse generation. Due to this motive, the sinusoidal pulse width modulation and space vector modulation are employed to minimize the losses and easy to implement. THD of converter decided by switching frequency of the power devices and maximum power transfer level depends on the nature characteristics of the controller [15].

Single/ three phase IM widely used in home and industrial applications especially at low power ranges (below $2.5 \mathrm{~kW}$ ). These type of motors used in variable speed applications, so it requires variable voltage which can be obtained through matrix converter. For this type of applications, inverter used with symmetric voltage magnitude and frequency and needs of large dc link capacitors and rectifier circuit. But matrix converter act as a direct ac-ac converter, which has sinusoidal input current and adjustable output voltage and frequency.

This projected work elucidates performance of 3-phase matrix converter using space vector pulse width modulation to control operation of three phase induction motor. It minimizes the effect on the harmonic fluctuation in AC output voltage and stress on the power switch is reduced.

\section{THREE PHASE MATRIX CONVERTER}

\subsection{Structure}

The matrix converter includes 9 bidirectional switches, which allows any output phase voltage is connected to any input phase voltage. The input 3 phase terminal voltage is connected with three phase bidirectional switch that reduction in harmonic fluctuation. DC link filters are capacitive filter and inductive filter are eradicated, due to that cost of system is decrease. 3-phase matrix converter is shown in Figure 1.

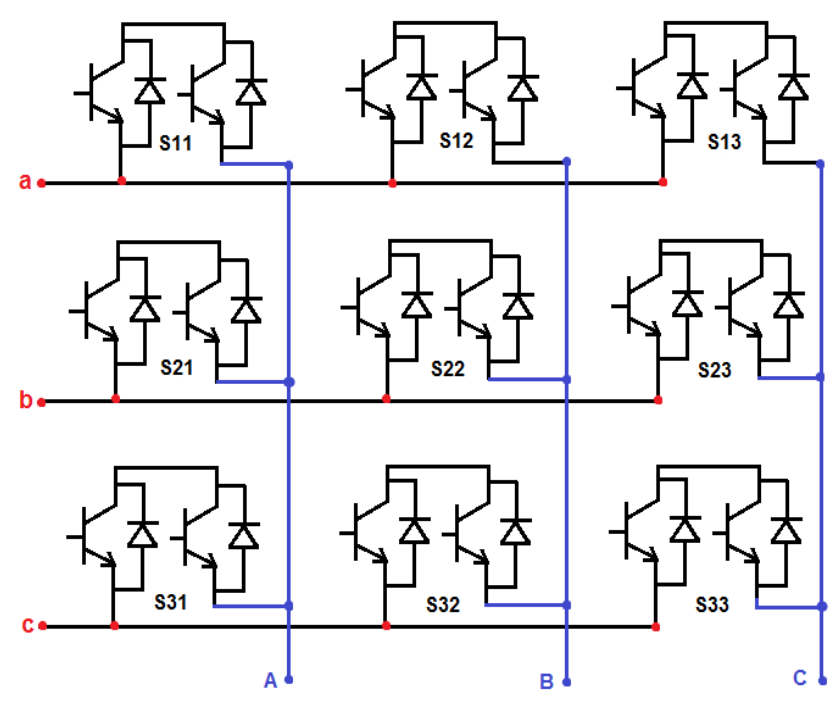

Figure 1. Three-phase matrix converter

\subsection{Operation of matrix converter}

The applied input instantaneous power will not be equal to output power. The difference between these input and output power should be absorbed or distributed by an energy storage devices like capacitor or inductor within the converter system. But matrix converter has single stage conversion unit with help of bidirectional switches instead of using multistage conversion and energy storage devices in the converter. Matrix converter with bidirectional switch is shown in Figure 2. Due to the absence of energy storage devices, the instantaneous input power is equal to output power with ideal zero loss switches. The system consists of 9 bidirectional switches, which are connected as three groups. Each group contains 3 switches and each bidirectional switch is connected with both input voltage and output voltage.

Totally operation of 3 phase matrix converter has 27 permitted switching modes, in that 18 active vector modes, 3 zero vector modes, 3 normal vector modes and 3 inverse vector modes. In Figure 3 illustrates, a, b, c are input voltages for bi-directional switches and A, B, C are output voltages of matrix 
converter. Here all input phase voltages are connected to output phase voltage. And these bidirectional switches are switched $\mathrm{ON}$ rotational basis, which avoids switching of 2 switches in a same leg.

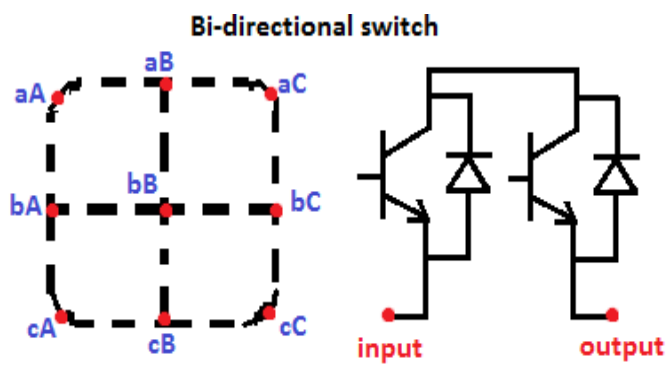

Figure 2. Matrix converter with bi-directional switch

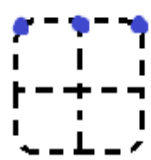

AAA<smiles></smiles>

BBB

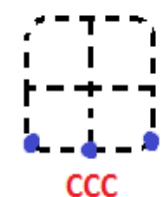

$\mathrm{CCC}$

Figure 3. Matrix converter - zero vector modes

In Figure 3 shows zero vector modes of 3 phase matrix converter and in that all output phases are connected in single input phase, which leads to damage the system because 3 phase load is connected with 1 phase input. The normal active vector and opposite vector modes are applicable for forward and reverse operation of induction motor.

\section{SPACE VECTOR MODULATION (SVM)}

SVM is a switching control method for the power electronic switches which recognize the switching sequences by assignment of a switching vector in d-q space region [16]. It is enhanced at harmonic content level diminution and increasing output voltage amplitude as contrast to traditional SPWM (Sinusoidal Pulse Width Modulation), which is generally used. It diminishes the common mode voltage which is the difference between vector sum of the voltage level potential at power converter system output and ground point [17]. The voltage across proposed matrix converter has minimised voltage fluctuation and reduced harmonic input current source. Space vector representation for 3-phase power converter is shown in Figure 4.

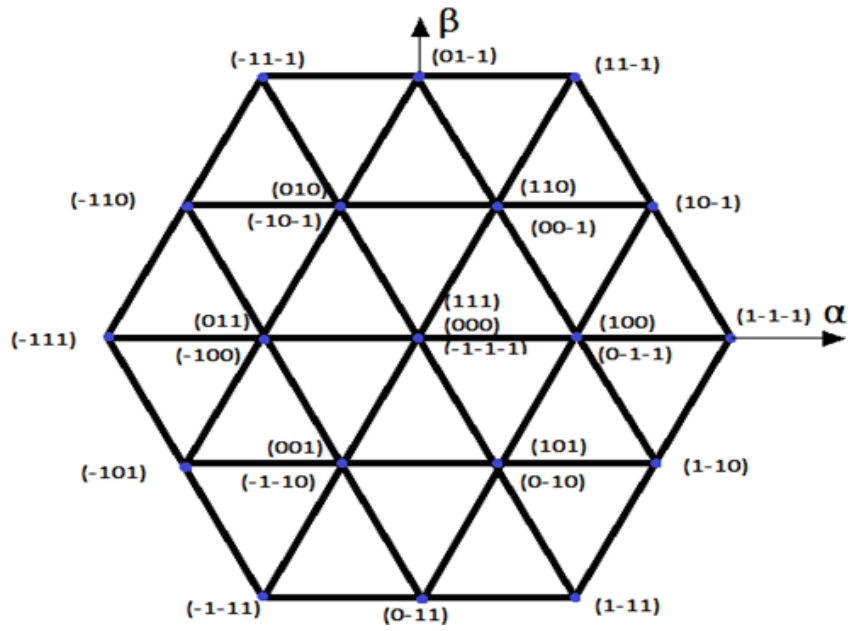

Figure 4. Space vector representation for 3-phase power converter 


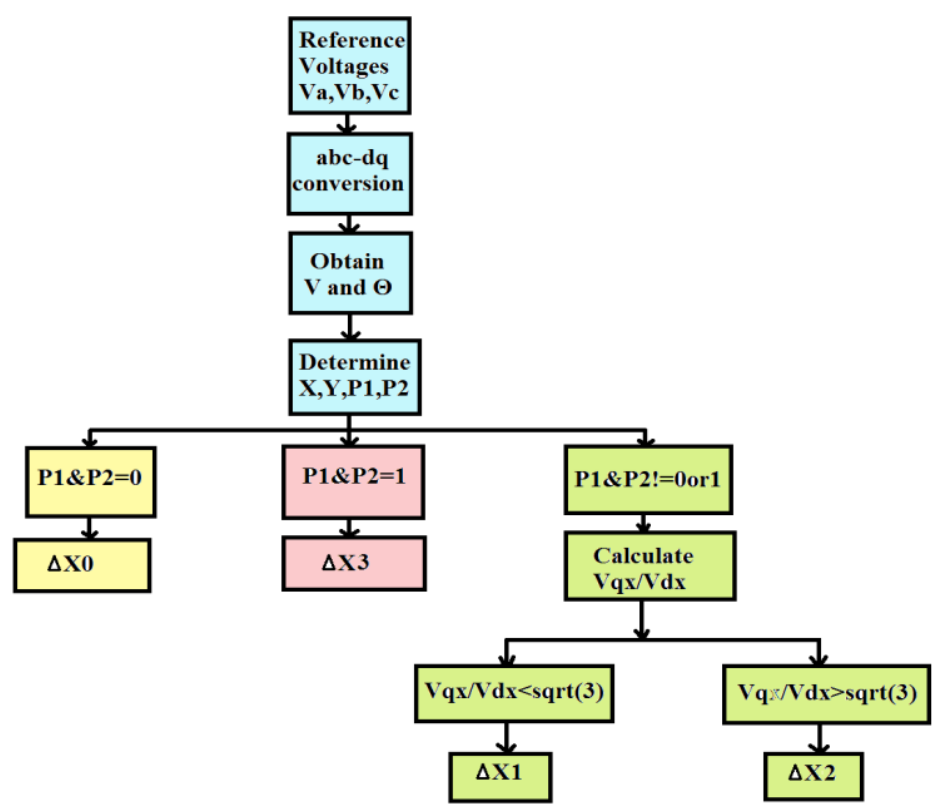

Figure 5. Flowchart for switching pulse generation using SVPWM method

For determining the switching state vectors of matrix converter, the space vector illustration is divided into The following steps are used to generate the gating pulses for bi-directional switches of matrix converter. The folwchart is shown in Figure 5, in that X \& Y parameters used to find the sector identification, P1 \& P2 are used to identify the triangle for reference vector calculation. The steps are,

a. Sector identification for reference vector placed based on magnitude and angle calculation

b. Triangle identification in the sector region

c. Switching vector calcuation

d. Switching pulse generation for bi-directional switches placed in matrix converter.

e. Obtained variable output voltage and current with reduced harmonic level of $0.31 \%$ \& $0.34 \%$ respectively.

f. Voltage stress across bi-directional switch is controlled with help of SVM technique.

\section{SIMULATION RESULTS AND DISCUSSION}

The simulation of the projected system was designed in Matlab/simulink16a. Three phase matrix converter connected with an input voltage of $230 \mathrm{~V}$. Fixed three phase voltage converted into variable voltage and variable frequency through smart technology matrix converter with help of bi-directional switches.

In Figure 6 shows 3-phase output voltage of matrix converter with $219 \mathrm{~V}$ is converted from fixed three phase input voltage of $230 \mathrm{~V}$ is shown in Figure 7. And three output current of 13.7A, which is exposed in Figure 8. Harmonic content \& voltage stress of proposed system is minimised with bi-directional switches, harmonic analysis for variable 3-phase output voltage of $0.31 \%$ and for 3-phase output current of $0.34 \%$ is shown in Figure 9 \& Figure 10 respectively. 


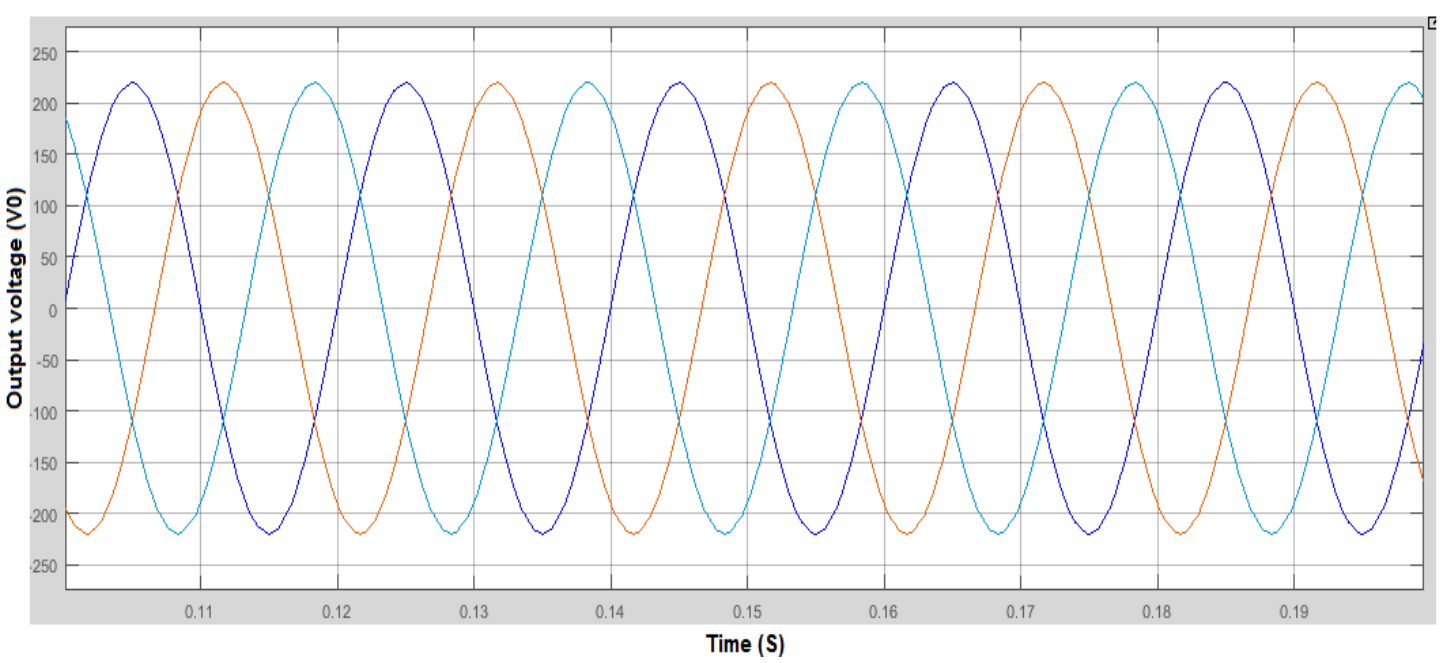

Figure 6. 3 phase variable output voltage of matrix converter

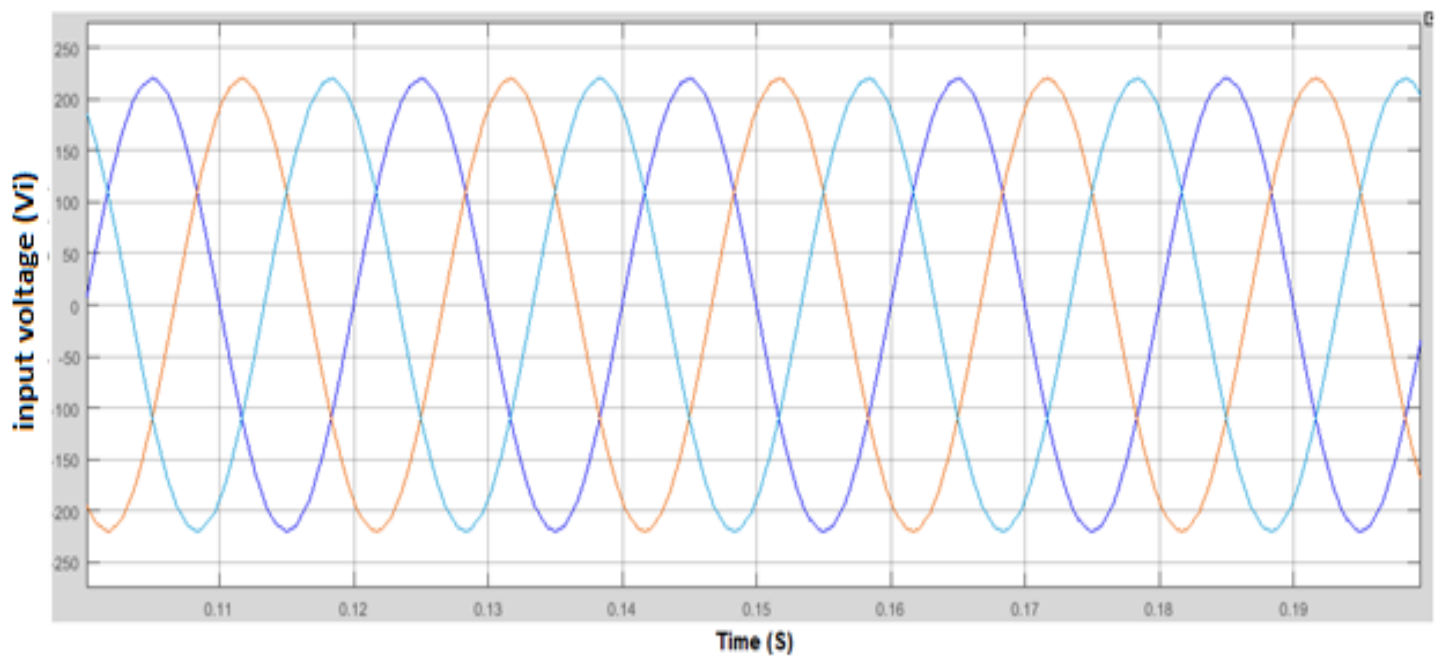

Figure 7.3 phase input voltage of matrix converter

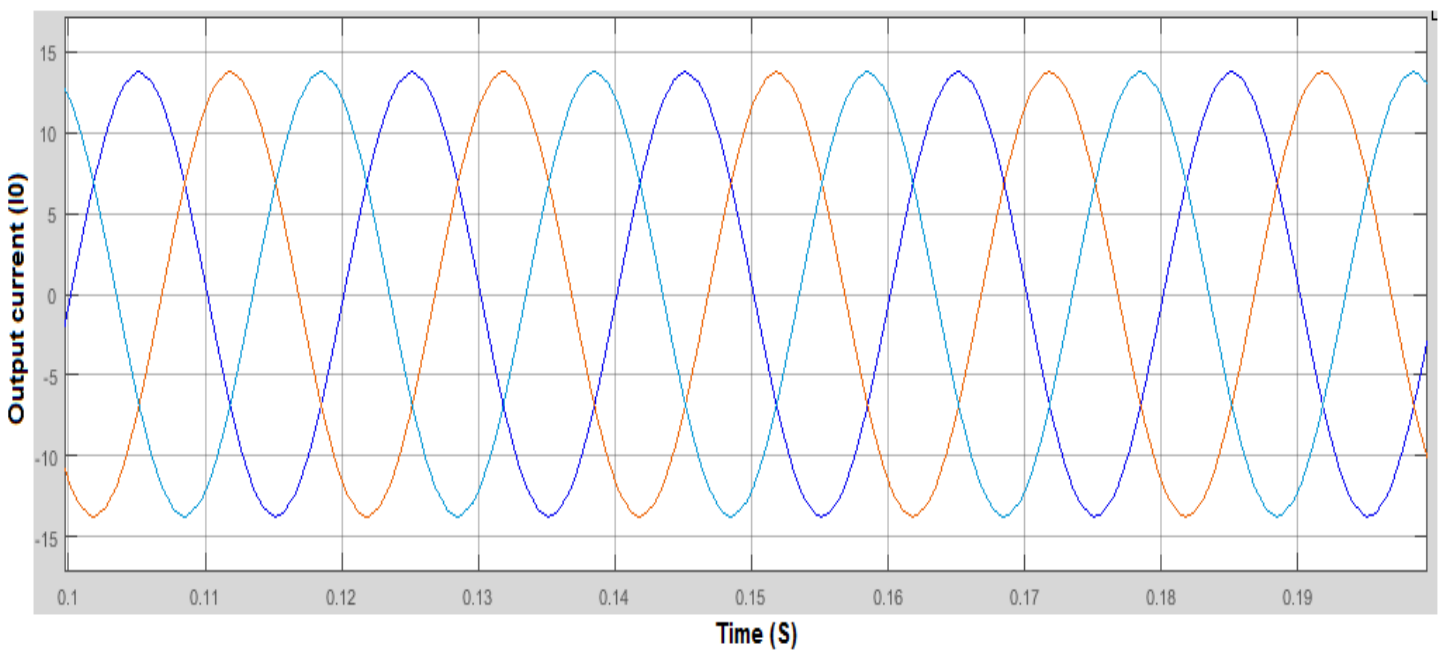

Figure 8.3 phase output current of matrix converter 


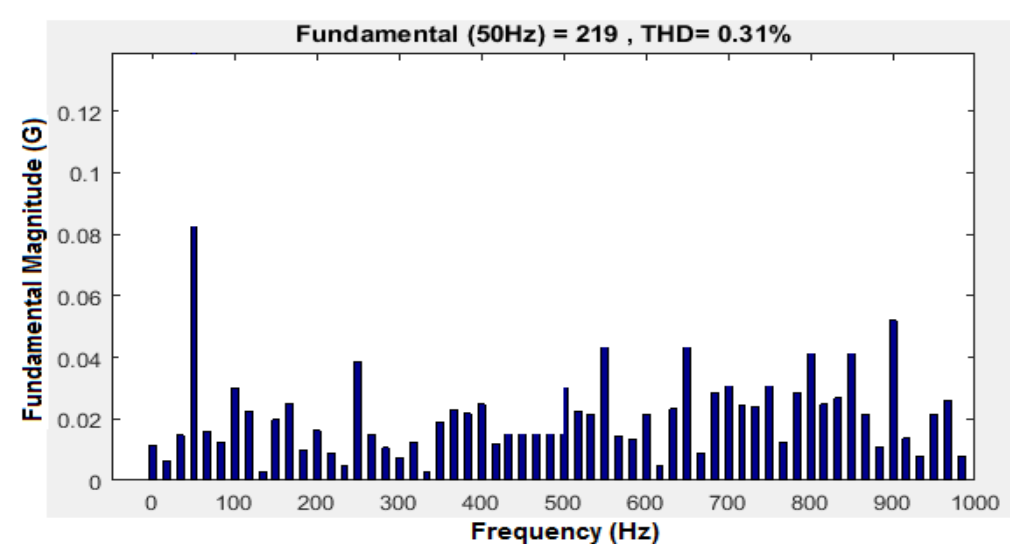

Figure 9. THD analysis for variable output voltage

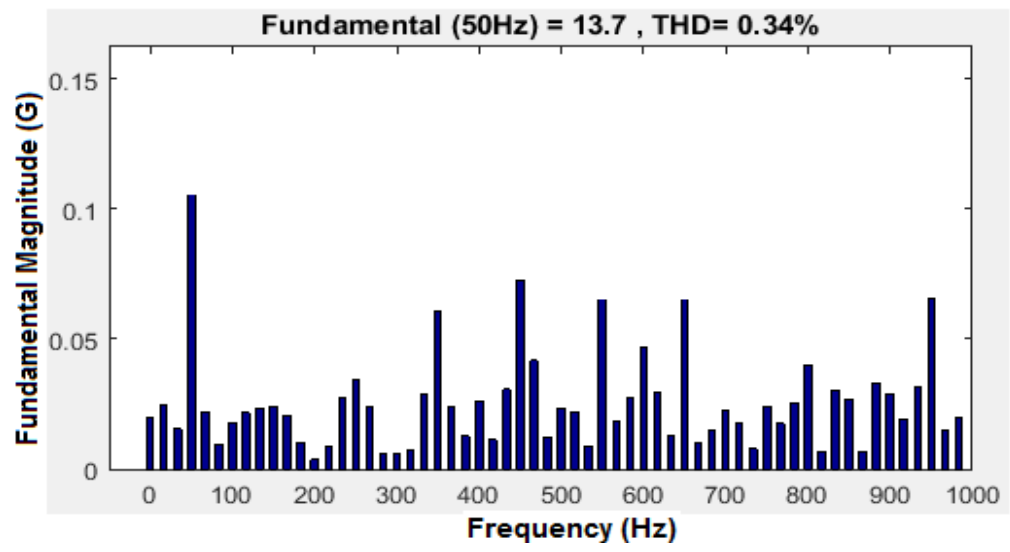

Figure 10. THD analysis for output current

In Figure 11 shows the comparison between applied 3-phase input voltage and 3-phase output voltage. In Figure 12 shows input current of matrix converter, which contains more fluctuation. Ageing factor of power converter depends on voltage stress on the power switches, Figure 13 shows voltage stress across all the bi-directional switches placed in proposed converter. Basically any PWM technique output of all phases are in the form pulses wave, so CMV consists of high switching frequency voltage pulses wave of assured magnitude which emerges between with phase and the ground point.
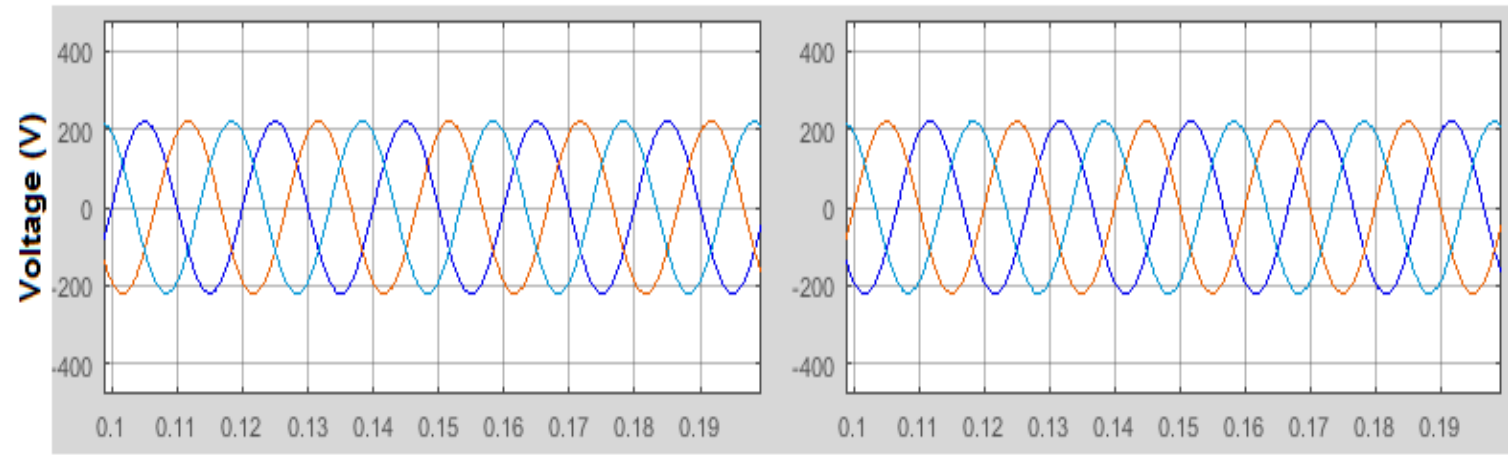

Time (S)

Figure 11. Comparison between input voltage \& output voltage 


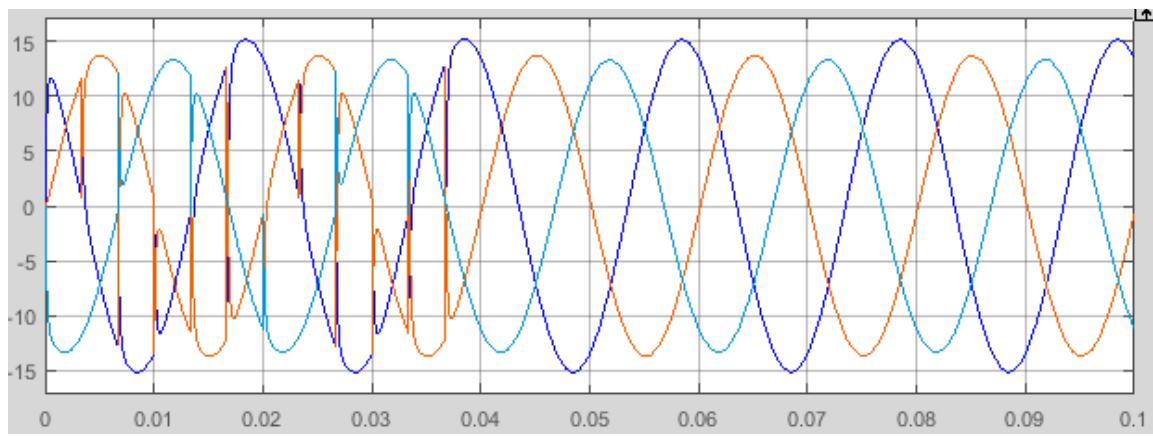

Figure 12. Input current of matrix converter with 3-phase IM drive

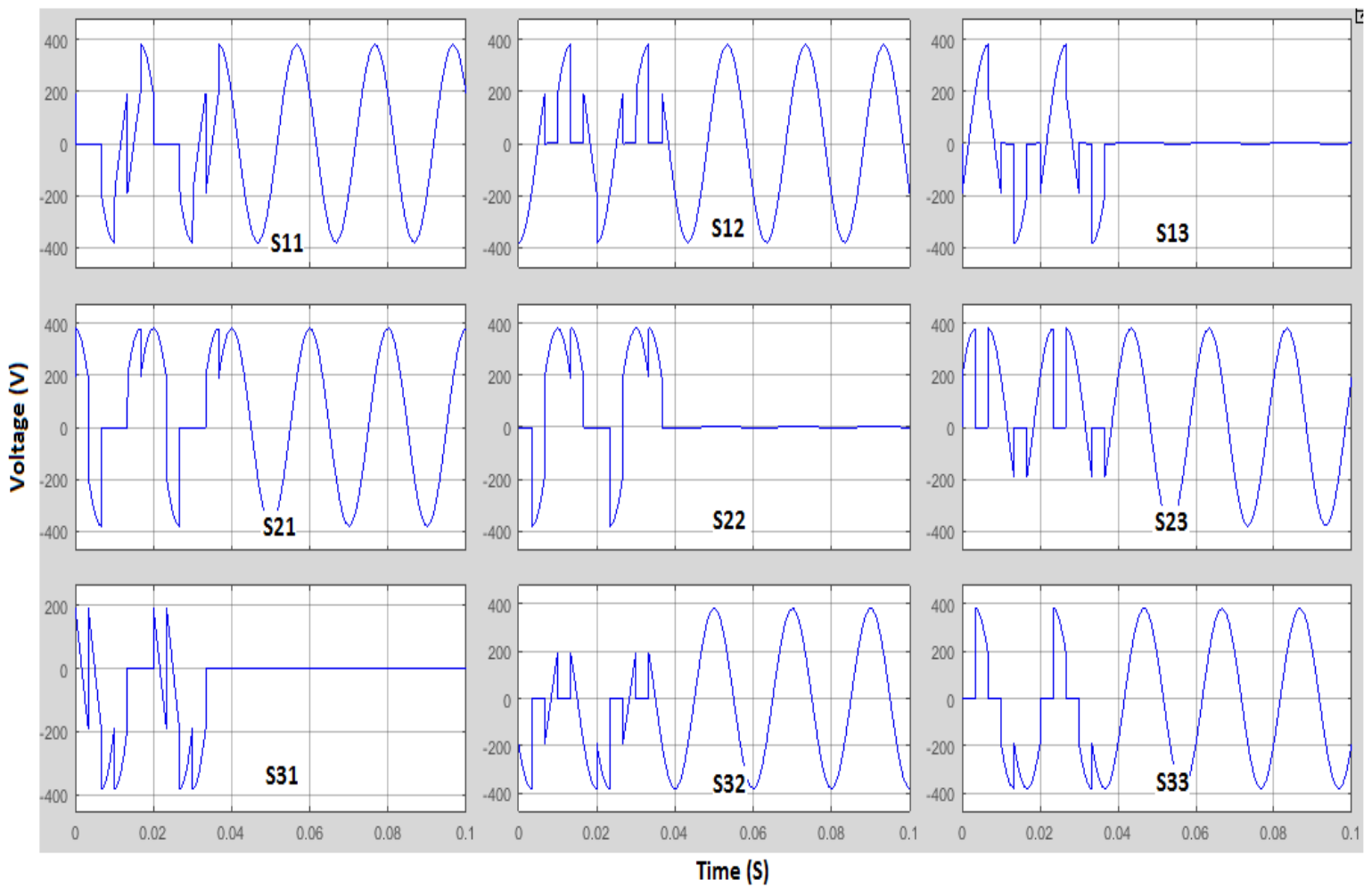

Figure 13. Voltage stress across bi-directional switches (S11, S12, S13, S21, S22, S23, S31, S32, S33)

\section{CONCLUSION}

This work described about simulation of 3-phase matrix converter using space vector modulation. Matrix converter designed to produce variable voltage and variable frequency with help of filtered input voltage and due to that current harmonics also minimised in the projected system. Voltage across the bidirectional switches and common mode voltage is reduced with assist of SPWM switching pulse generator. The proposed scheme was simulated using matlab/simulink. The following qualities are premeditated from this proposed system.

\section{REFERENCES}

[1] R. Gupta, K. Mohapatra, A. Somani "Direct matrix converter-based drive for three-phase open-end-winding ac machine with a advanced features," IEEE Trans. Ind. Electron., vol. 57, no. 12, pp. 4032-4042, Dec. 2014.

[2] R. Lai et al., "A systematic topology evaluation methodology for highdensity three-phase PWM ac-ac converters," IEEE Trans. Power Electron., vol. 23, no. 6, pp. 2665-2680, Nov. 2010. 
[3] G. Mondal, K. Gopakumar, P. N. Tekwani, and E. Levi, "A reduced switch- count five-level inverter with common-mode voltage level elimination for an open-end winding induction motor drive," IEEE Trans. Ind. Electron., vol. 54, no. 4, pp. 2344-2351, Aug. 2012.

[4] R. Palanisamy, K. Vijayakumar, Komari Nikhil, Madhumathi Iyer and Ramachandar Rao, "A Proposed SVM for 3 level Transformer-less Dual Inverter Scheme for Grid Connected PV System”, Indian Journal of Science and Technology, Vol 9(42), DOI: 10.17485/ijst/2016/v9i42/101834, November 2016.

[5] H. Keyhani and H. A. Toliyat, "A soft-switched three-phase ac-ac converter with a high-frequency ac link," IEEE Trans. Ind. Appl., vol. 50, no. 4, pp. 2637-2647, Jul. /Aug. 2014.

[6] Boztas, G, "A novel direct AC-AC converter for single and two-phase asynchronous motors," MSc thesis, Firat University, 2016.

[7] J. Lei, B. Zhou, X. Qin, J. Wei, and J. Bian, "Active damping control strategy of matrix converter via modifying input reference currents," IEEE Trans. Power Electron., vol. 30, no. 9, pp. 5260-5271, Sep. 2016.

[8] L. Empringham, J. Kolar, J. Rodriguez, P. W. Wheeler, and J. C. Clare, "Technological issues and industrial application of matrix converters: A review," IEEE Trans. Ind. Electron., vol. 60, no. 10, pp. 4260-4271, Oct. 2013.

[9] J. Rodriguez, M. Rivera, J. W. Kolar, and P. W. Wheeler, "A review of control and modulation methods for matrix converters,” IEEE Trans. Ind. Electron., vol. 59, no. 1, pp. 58-70, Jan. 2012.

[10] R. Palanisamy, K. Vijayakumar, "SVPWM for 3-phase 3-level Neutral Point Clamped Inverter fed Induction Motor Control," Indonesian Journal of Electrical Engineering and Computer Science(IJEECS), vol. 9, no. 3, pp. 703-710, March 2018.

[11] B. McGrath, D. Holmes, and T. Lipo, "Optimized space vector switching sequences for multilevel inverters," IEEE Trans. Power Electron., vol. 18, no. 6, pp. 1293-1301, Nov. 2013.

[12] K. Gupta and A. Khambadkone, "A Space Vector PWM Scheme for Multilevel Inverters Based on the Two-Level Space Vector PWM,” In: IEEE Transactions on Industrial Electronics, vol. 53, no. 5 (2013).

[13] Y. Yan, H. An, T. Shi, and C. Xia, "Improved double line voltage synthesis of matrix converter for input current enhancement under unbalanced power supply," IET Power Electron., vol. 6, no. 4, pp. 798-808, Apr. 2013.

[14] Li, X., Su, M., Sun, Y., et al., "Modulation strategies based on mathematical construction method for matrix converter under unbalanced input voltages", IET Power Electron., 2013, 6, (3), pp. 434-445.

[15] S. Aldhaher, P. C. K. Luk, A. Bati, and J. F. Whidborne, "Wireless power transfer using class e inverter with saturable dc-feed inductor," IEEE Trans. Ind. Appl., vol. 50, no. 4, pp. 2710-2718, Jul./Aug. 2014.

[16] R. Palanisamy, K. Vijayakumar, D.Selvabharathi, "MSPWM Based Implementation of Novel 5-level Inverter with Photovoltaic System", International Journal of Power Electronics and Drive System (IJPEDS), vol. 8, no. 4, pp. 1494-1502, December 2017.

[17] H. Nguyen and H. Lee, "A DSVM method for matrix converters to suppress common-mode voltage with reduced switching losses,” IEEE Trans. Power Electron., vol. 31, no. 6, pp. 4020-4030, Jun. 2016. 